\title{
Pontevedra, a cidade que floreceu na Baixa Idade Media: adentrándonos na dieta medieval a través dos restos humanos
}

\author{
Olalla López-Costas* \\ EcoPast (GI-1553), Área de Arqueología, Dpto. de Historia, \\ Universidade de Santiago de Compostela
}

DOI: 10.17075/gtax.2021.004 
* A autora deste traballo está financiada polo proxecto «Pollutio», Plan Nacional Retos JIN 2019 (PID2019-111683RJ-I00), Ministerio de Ciencia e Innovación, e pola Beca Leonardo a Investigadores y Creadores Culturales 2020 da Fundación BBVA, «Las epidemias del hambre». 


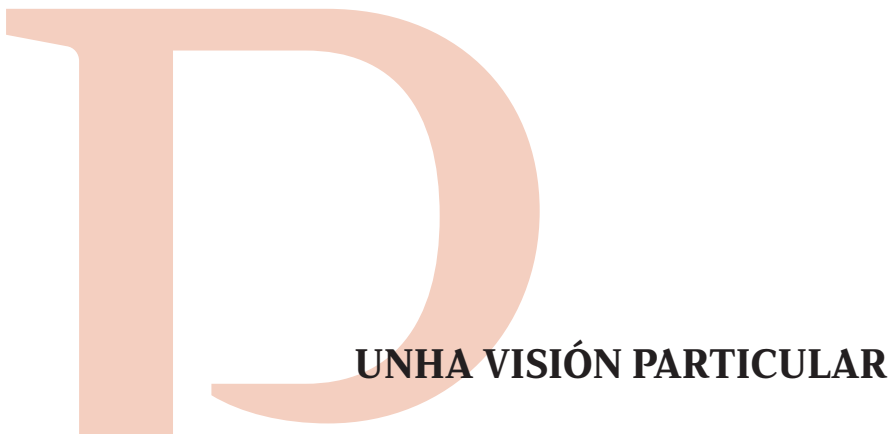

Parece ser que segundo a consciencia popular nada sucedía en Galicia nos tempos de Afonso X. Pénsase que mentres en Castela se loitaba, se repoboaba e medraban as cidades, Galicia permanecía imperturbable co dominio da nobreza e a Igrexa, con pouco máis que dicir. Nada máis lonxe da realidade, o século XIII foi determinante en moitas áreas de Galicia e viu entre outras cousas florecer as urbes gremiais. Entre elas destaca o crecemento dunha vila mariñeira nas Rías Baixas que tivo nese século quizais o máis grande esplendor económico da súa historia: Pontevedra. Este progreso sucedeu grazas en parte á acción dos reis Fernando II e Afonso X, que promoveron que se alzase este lugar como un centro de comercio de recursos mariños de primeira orde, así como a xestión do señorío compostelán e do concello. Para iso adentrareime na historia desta vila a través dos seus habitantes e a dieta que mantiñan, xa que na Pontevedra medieval os reis, o peixe e a dieta formaban un todo.

Tratarei nos próximos parágrafos de condensar a información que temos desta cidade mariñeira por excelencia de Galicia, pero a través dunha visión moi particular. Pontevedra tivo ata agora uns cronistas excelentes como José Armas Castro (1992) ou Juan Juega Puig (2012), entre moitos outros homes e algunha muller dos que irei citando traballos. A súa historia baséase na información documental que se preservou da Pontevedra medieval e constitúe un corpus magnífico para facernos unha idea do carácter, da economía e da evolución da cidade. Neste caso, eu collo o relevo comparando a historiografía cos datos obtidos a través dun rexistro moi particular, os restos óseos humanos. Debo confesar neste punto que o libro que Armas Castro publicou en 1992 foi desde o principio unha guía nas miñas investigacións e resulta eminentemente sorprendente a coincidencia dos datos obtidos a partir da información documental cos analizados no rexistro arqueolóxico. Constitúe Pontevedra, polo tanto, un exemplo paradigmático de como arqueoloxía e historiografía camiñan polo mesmo sendeiro, moitas veces sen tocarse, pero de seguro obtendo resultados complementarios. A miña «historia da Pontevedra medieval» está sustentada na propia xente que a fixo florecer, nos seus corpos e no testemuño que constitúen os seus esqueletos.

Nas escavacións de mediados da década dos 2000 nas que participei como especialista en osteoarqueoloxía (2007-2010) atopáronse restos humanos ben conservados en tres das necrópoles do centro de Pontevedra: Santa María a Maior 
ou dos Pescadores, San Bartolomeu O Vello e San Domingos. Empréganse eses restos neste traballo, xunto coa descrición das súas áreas funerarias para facer unha reconstrución do día a día da vila durante os séculos XIII ao XV a través dun exemplo, que é a reconstrución da súa dieta. Analízase tamén o papel que tiveron os reis, entre eles Afonso X e Fernando II, no aflorar desta vila galega.

\section{OS ESTUDOS EN RESTOS HUMANOS}

O traballo con restos humanos, normalmente esqueletos, de contextos arqueolóxicos é unha disciplina que desde hai máis de século e medio vén reconstruíndo o día a día das persoas que viviron hai centros e miles de anos (para España, ver Campillo 1993, Márquez-Grant et alii 2011). Recibe múltiples nomes que van de osteoarqueoloxía, antropoloxía física, antropoloxía biolóxica, osteoloxía ou bioarqueoloxía no mundo anglosaxón. Ao contrario do que popularmente se cre, un esqueleto «fala» moito máis da vida da persoa que da súa morte (Campillo 1993). Isto débese a que a súa forma e a composición están máis condicionadas polo transcurso da vida do individuo, sendo a morte algo momentáneo, case ínfimo, no relato dese ser. Xa que logo, o esqueleto dunha persoa informa sobre a súa saúde e o seu benestar, os cambios na dieta e mobilidade, algúns trazos da súa actividade e o seu perfil biolóxico incluíndo o sexo, a idade e as características físicas. Se contamos cun número representativo de individuos dunha poboación, poderemos ademais empregar esta información para reconstruír o perfil demográfico e as características «máis físicas» da sociedade (Larsen 2002). Este último salto, intentando entender as poboacións humanas no canto dos individuos, supuxo unha revolución na maneira de traballar con esqueletos humanos de contextos arqueolóxicos e permitiunos abrir fiestras directas á vida no pasado (Wood et alii 1992). Unha sociedade é moito máis que un conxunto de individuos, polo que só se pode comprender cando se consideran os aspectos supra-individuais, esta maneira de traballar coñécese como o uso dunha perspectiva poboacional.

A finais do século pasado, tras a revolución que supuxo comezar a considerar a perspectiva poboacional, os avances técnicos no estudo de esqueletos fixeron que a investigación tornase nunha hiper-especialización que permitiu adentrarnos nos detalles máis concretos das técnicas e da súa aplicación. Os equipos de traballo vencellábanse a unha técnica ou tipo de estudos concreto realizando análises centradas na antropoloxía física ou na osteoloxía con pouca conexión con outras disciplinas como a historia ou a arqueoloxía. Foron aparecendo cada vez máis os traballos multidisciplinares que combinan especialistas de varias ramas para acadar obxectivos comúns. Non obstante, nos últimos dez anos e cara ao futuro, os avances semellan adentrarse na interdisciplinariedade ou transdisciplinariedade, acadando unha cone- 
xión máis real entre os varios saberes para coñecer mellor o obxecto ou o período que intentamos entender. É dicir, xa non somos varios especialistas contando os resultados e buscando nexos, senón que os estudos nacen xa empregando aproximacións de varias fontes e a historia e arqueoloxía son consideradas no deseño desde o principio. Esta transdiciplinariedade permite acadar metas máis complexas, como pode ser a visión holística da alimentación na vila de Pontevedra.

Hoxe en día existen moitas maneiras de estudar os «mortos» para reconstruír a vida: desde as máis clásicas como poden ser as medidas (antropometría) ou as características morfolóxicas (estudos macroscópicos de enfermidades) ata as máis modernas baseadas na composición química (isótopos estables) ou molecular (espectroscopia ou ADN). Todas experimentaron un avance considerable nos últimos anos grazas ao abaratamento e á mellora das técnicas analíticas (tales como as xenómicas ou as análises en espectrómetros de masas) e aos avances informáticos que permiten traballar con datos múltiples e complexos. Existen, polo tanto, moitos tipos de análises, mais dentro das particularidades da maneira de vivir que quedan reflectidas nos restos óseos, a saúde, o crecemento e a alimentación son, probablemente, as máis importantes.

Un tipo de traballo no que se vén avanzando moito nos últimos anos é o dos estudos bioxeoquímicos, entre eles as análises de isótopos estables para reconstruír a dieta e a mobilidade. As diversas partes do esqueleto fálannos de momentos da vida diferentes, ao renovarse continuamente no caso dos ósos podemos reconstruír os últimos anos de vida, mentres que é posible achegarse á infancia analizando os dentes, xa que estes se forman no crecemento e permanecen case inalterables. Os estudos de isótopos estables para a paleodieta son posibles mediante a extracción dunha molécula moi resistente e abundante que se preserva no esqueleto, o coláxeno, e a posterior medición dos seus aspectos isotópicos calculando a proporción que hai de carbono-13 e $12\left(\delta^{3} \mathrm{C}\right)$ e de nitróxeno-15 e $14\left(\delta^{15} \mathrm{~N}\right)$. Como son estables, estes non varían co paso do tempo (como sucede co carbono-14, ${ }^{14} \mathrm{C}$ ). Como moitos alimentos teñen uns valores característicos, os aspectos dos humanos van depender da proporción destes alimentos nas diversas comidas. Así, o sinal característico do esqueleto dunha persoa vai estar determinado polo tipo e proporción de alimentos consumidos.

No referente a España, aínda que os estudos de esqueletos humanos e de paleopatoloxía (estudo das enfermidades ou patoloxías antigas) comezaron un pouco máis tarde que noutras áreas de Europa, como Francia, o avance foi constante e con bo paso. Destacan a produción de varias teses centradas en reconstruír a vida de áreas xeográficas concretas; por exemplo, para Galicia. a feita polo doutor José Carro Otero (1971) ou a miña propia varios anos despois (López-Costas 2012); mentres que na última década están vendo a luz traballos doutorais máis centrados na resposta de hipóteses concretas que alcanzan un maior impacto internacional, tales como a dieta ou a contaminación por mercurio (ex. López-Costas/Müldner 2019, Álvarez-Fer- 
nández et alii 2020). En Galicia somos uns cantos especialistas os que dedicamos a vida profesional ao estudo desta disciplina. Moitos investigadores, e cada vez máis investigadoras, traballamos analizando as necrópoles galegas tratando de reconstruír a vida diaria no pasado. Somos todos herdeiros de Miguel Fusté Ara, o que probablemente foi o primeiro antropólogo físico en realizar os seus estudos nesta esquina da Península. Fíxoo na coñecida necrópole da Lanzada e baixo o paraugas do Museo de Pontevedra (Blanco Freijeiro et alii 1961). Quizais o Padre Sarmiento, coas súas descricións deste xacemento, xa puxera a primeira pedra (Sarmiento 1950). O certo é que na actualidade, a pesar da mala conservación dos restos esqueléticos, Galicia é unha das áreas de España mellor estudadas, destacando, entre outros, pola cantidade de análises de isótopos estables para reconstruír a dieta. De seguro, no futuro próximo as antropólogas, bioarqueólogas, osteólogas ou calquera dos moitos sinónimos que ten a nosa profesión seguirán producindo información sobre os modos de vida no pasado. Coma neste caso que expoño a continuación, axudándonos a recompoñer de que maneira unhas decisións rexias cambiaron o devir de toda unha vila e dunha rexión.

\section{PONTEVEDRA E OS PRIVILEXIOS REAIS}

O burgo ou vila de Pontevedra non precisa presentación na xeografía galega. Capital de provincia, está situada ao fondo dunha das rías máis produtivas de Galicia, desde onde leva séculos vertebrando o devir da zona central das Rías Baixas e por extensión do sur de Galicia. Aínda que a orixe urbana de Pontevedra non está totalmente clara, parece que o comercio marítimo e o mar son de especial importancia (Méndez Martínez 1988). A ponte vella da cidade e a súa situación estratéxica no camiño de peregrinación cara a Santiago de Compostela son a outra razón de peso para acadar a protección real (Armas Castro 1992). No ano 1180 a cidade foi doada á Igrexa compostelá por Fernando II, o mesmo rei que no ano 1169 lle concede o foro real que impulsa o seu crecemento (López Ferreiro 1895: 162). Os privilexios a partir deste momento non paran de sucederse; entre outros, a redución da pena por naufraxio aos barcos desta cidade en todo o reino de León por Fernando II (Armas Castro 1992: 53).

Sucedeu que no ano 1229 o rei Afonso IX lle concedeu á vila de Pontevedra o privilexio sobre a seca, o transporte e a venda de peixe, así como o feito de ser o único porto de carga e descarga desde Baiona ata o norte (Méndez Martínez 1988). Outorgoulle expresamente a facultade de secar as pescadas e vendelas por mar e terra dentro e fóra do reino de León. O seu fillo Fernando III, no ano 1238, confirma estes dereitos e concédelle, xunto co porto de Noia, a exclusividade de fabricar saín de sardiña. Estas concesións son confirmadas posteriormente por Afonso X e Fernando IV. De feito, o foro de Fernando II puido chegar a nós grazas á carta de confirmación dos 
privilexios feita por Afonso X en 1264, que inclúe unha copia literal e que se conserva no Museo de Pontevedra (Fernández Villamil 1942, Armas Castro 1992).

A partir de 1250 a vila toma un goberno en forma de concello («grupo de homes bos») similar ao doutras vilas baixo a autoridade do arcebispo de Compostela, cunhas liberdades que lle van permitir adaptarse ao crecemento imparable da actividade no século XIII e XIV (López Ferreiro 1895). A cidade dedícase principalmente á preparación e exportación de pescada, congro e sardiña; moitas veces nos baixos das casas, mentres que outras capturas, como chocos e abadexos, estaban exentos de impostos para a xente de Pontevedra (Armas Castro 1992). O protectorado da mitra compostelá xunto cunha maior autoxestión dos recursos polo concello e a importancia dos gremios van facer que a cidade acade unha estrutura comercial óptima nestes séculos e medre de maneira vertixinosa. Curiosamente, as mesmas características xunto coa perda dos privilexios reais en favor doutros portos son, segundo Juega Puig (2012), as causas do ocaso de Pontevedra durante o século XVI e sobre todo no XVII. Este autor reflexiona sobre a imposibilidade súa de adaptarse ao dinamismo mercantil marcado polos portos sen ataduras feudais do norte de Europa, por exemplo en cousas tan sinxelas como mover o calendario pola presenza dos cardumes de sardiñas.

\section{OS BARRIOS, AS IGREXAS E OS CEMITERIOS DA VILA}

O núcleo inicial de poboación de Pontevedra xurdiu no burgo e ao redor da igrexa de Santa María, posteriormente chamada «Santa María a Maior» ou «a dos Pescadores». Distínguense no século XII dúas áreas, a vila amurallada e o arrabalde da Moureira. Este último sitúase na liña entre o río Lérez e o litoral e incluía as casas dos pescadores cunha conformación moi semellante entre elas (Méndez Martínez 1988), tendo estas un baixo destinado a taller de afumado de peixes ou á fabricación de saín. Na chamada «vila», as casas eran máis señoriais e mellor construídas (Méndez Martínez 1988) e desde o século XIII estaban rodeadas por unha muralla de pedra, da que se atoparon abundantes vestixios arqueolóxicos. Neste século, o aumento de poboación dentro da muralla fai que se cree unha nova freguesía, San Bartolomeu -posteriormente, «San Bartolomeu o Vello»-, e o Burgo pequeno fóra dela. Ao saír pola porta sur está o campo de San Domingos (hoxe, a Praza de España), onde se situaba o convento homónimo. A muralla vai definir os espazos, pero tamén as clases sociais. De maneira xeral, os habitantes máis pobres sitúanse nos arrabaldes exmuros, sobre todo na Moureira, mentres que no interior da vila vivían as familias aristocráticas e as pertencentes aos diversos gremios (Armas Castro 1992: 241).

Os privilexios reais fan que floreza a pesca de baixura e aumente a demografía. Empezan a chegar emigrantes doutras áreas de Galicia e a asentarse co- 
merciantes e artesáns. O aumento demográfico vai continuar de maneira imparable ata chegar ao máximo no século XV (Armas Castro 1992). Outro dato da intensidade comercial é que Pontevedra conta desde mediados do século xiII cun mercado semanal e unha feira anual en setembro na área baleira ao redor de San Bartolomeu. De feito, próximos ou rodeando as igrexas de Santa María, San Bartolomeu e San Domingos aparecen espazos sen casas adicados a cemiterio, onde se fan actividades como as xuntanzas veciñais ou gremiais, ademais do citado mercado (Armas Castro 1992: 95).

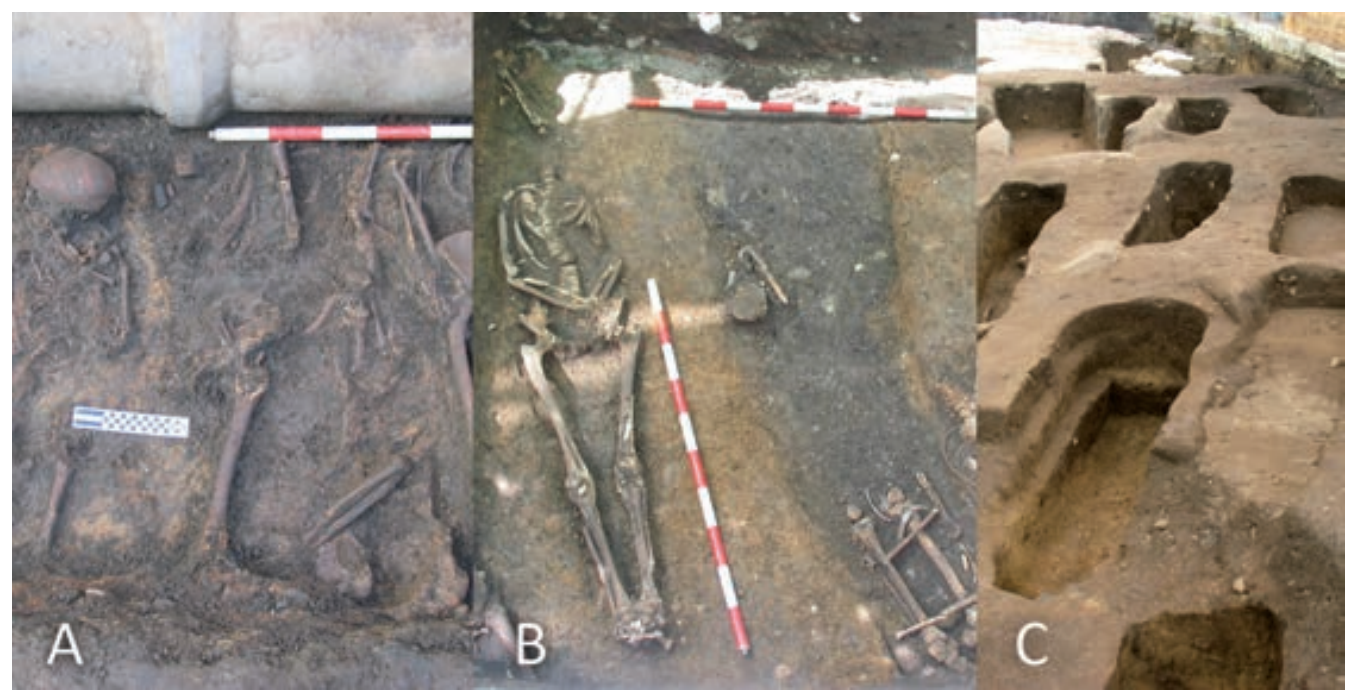

Fig. 1. Escavacións arqueolóxicas de inhumacións nas necrópoles de Santa María (A), San Bartolomeu (B) e San Domingos (C), onde se observa o diferente uso do espazo e a distribución dos enterramentos e restos humanos.

Dos varios cemiterios de Pontevedra, tres foron escavados nos últimos vinte anos e contan con estudos osteoarqueolóxicos dos esqueletos. Deses tres, dous pertencen ao interior das murallas da vila e outro ao exterior. As necrópoles escavadas abranguen enterramentos datados maioritariamente entre os séculos XIII e XV, e chegan, no caso de Santa María, ata o século XVII nos seus enterramentos cotiáns. Os cemiterios de Santa María e San Bartolomeu foron escavados de maneira conxunta durante varias intervencións, as máis prolongadas no tempo corresponden aos anos 2007 e 2008 (Constela Doce 2007, Chao Álvarez 2008), mentres que o de San Domingos foi intervido nos anos 2008 e 2009 (Constela Doce 2008). A historiografía indica que a nobreza e a burguesía máis acomodada prefiren os espazos conventuais para 
facerse enterrar ou no interior dos templos da cidade, mentres que a clase media e a baixa se fan inhumar no camposanto que rodea as igrexas (Armas Castro 1992: 266). As tumbas do interior da muralla están vencelladas ás fraternidades que tiveron un elevado carácter relixioso desde os ordenamentos de Afonso X en 1252, que prohibe os procesos organizativos (ordenamentos de burgos onde se vetaban as coalicións e ligas, e só se permitían cando tiñan un motivo caritativo ou funerario). As fraternidades ofrécenlles ás familias o pagamento do funeral e do enterro, polo que terminan por xestionar os camposantos (Armas Castro 1992: 168-170). Polo tanto, e como explicarei deseguido, baseándonos nos documentos, os esqueletos do cemiterio que rodean a Santa María e San Bartolomeu relacionaríanse coa clase media e con actividades de pesca e artesanía, respectivamente; mentres que en San Domingos poderiamos agardar persoas dunha clase social lixeiramente máis elevada.

A de Santa María é unha igrexa que pertence ao gremio dos mareantes ou todas as profesións relacionadas co mar, desde pescadores ata patróns. A igrexa actual foi levantada a cargo dese gremio no ano 1559 sobre unha anterior románica (Filgueira Valverde 1991). Nas escavacións de 2007 e 2008 atopáronse os alicerces dela, que cortaban varias tumbas, polo que sabemos que o cemiterio conservado é anterior. Os enterramentos rodean completamente a igrexa e as áreas de escavación situáronse na zona oeste onde se fixeron varias sondaxes: unha gran sondaxe na entrada norte (S.8) e, sobre todo, na fachada que dá cara ao leste (Constela Doce 2007, Chao Álvarez 2008). A Sondaxe 8 era extremadamente profunda e nos primeiros metros de terra descubriuse unha fosa común datada no século XVII-XVIII, onde se atoparon 22 esqueletos enterrados en dúas camadas de terra nunha mesma fosa (López-Costas 2012). O resto da sondaxe proporcionou restos óseos sen conexión anatómica presumiblemente atribuíbles a finais da Idade Media ou primeiros da Moderna, polo que se trataba de remocións de terra (debido á fragmentación e falta de individualización non se incluíron nos estudos antropolóxicos poboacionais). Na zona do leste e nas partes das fachadas do norte e do sur que lindan con esta, descubríronse numerosos enterramentos e deposicións secundarias que falan dun aproveitamento do terreo intenso. Ao contrario que no mundo islámico, os cemiterios cristiáns de clase social media-baixa destacan por un uso do espazo intenso con enterramentos duns por riba doutros, cortando fosas anteriores e situando os ósos ao lado do novo corpo (fig. 1). Todos os enterramentos escavados en Santa María estaban orientados en sentido oeste-leste, seguindo a liña marcada pola ábsida da igrexa. Ningún dos individuos tiña enxoval, salvo algúns alfinetes que poderían relacionarse cos sudarios de enterramento. Nenos, mulleres e homes compartían espazo sen diferenza de sexo ou idade. Nestas áreas, e excluíndo os enterramentos da fosa común, púidose recuperar un total de 60 individuos cunha conservación suficiente para estimar o sexo e a idade de cada un deles (López-Costas 2008, López-Costas 2012), os outros restos óseos presentaban un estado de conservación moi deficiente ou tratábase de grandes osarios que non permitían a individualización. 
Entre mediados e finais do século XIII, o templo de Santa María queda pequeno e xa non pode acoller os habitantes dunha vila en continua expansión. Os gremios dos artesáns acollen cada vez a máis familias e deciden fundar un novo templo ao que asociarse e onde facerse enterrar. Trátase de San Bartolomeu («o Vello»), que acolle principalmente os gremios de carpinteiros, toneleiros, pedreiros e ferreiros. As escavacións de 2007 e 2008 descubriron dúas áreas de enterramento separadas por un muro. Ao norte da igrexa vese unha área menos coidada que suxire unhas inhumacións de persoas con menores recursos; a preservación dos esqueletos aquí é moi deficiente, polo que non podemos saber moito máis das súas características. Preto da entrada principal ao leste escavouse no ano 2007 a chamada «sondaxe 16», que se caracterizaba de novo por esqueletos sen enxoval e dispostos en sentido oeste-leste e que reutilizan o espazo, pero de maneira menos intensa que en Santa María (fig. 1). Nenos, mozos, maiores, homes e mulleres comparten espazo cunha distribución que suxire unidades familiares (aínda que sen probas empíricas). Neste xacemento recuperouse un total de 20 esqueletos, ben conservados e individualizados e numerosos pertencentes a área norte-leste, cunha conservación moi deficiente (López-Costas 2008, López-Costas 2012). A igrexa de Santo Bartolomeu foi derruída e no mesmo soar e con case a mesma planta atópase hoxe o Teatro Principal.

Finalmente, ás aforas da muralla situábase o convento de San Domingos. As ruínas do convento son visibles e o cemiterio está baixo a Praza de España. Nos anos 2008 e 2009, as obras dun aparcadoiro subterráneo fixeron que se escavase esta necrópole (Constela Doce 2008). Apareceron entón unha serie de fosas de inhumación perfectamente organizadas en liñas cabeza-pés, con sentido norleste-suroeste. A adscrición cronolóxica sitúase posiblemente no baixomedieval, aínda que é complicada debido á falta de enxoval e á mala preservación que non permite a datación por ${ }^{14} \mathrm{C}$. Un dos esqueletos foi atopado cun rosario nas mans, namentres que o o resto se atopou sen enxoval. Neste caso, os corpos non eran depositados directamente sobre a terra cun sudario coma nos anteriores, senón que son visibles os negativos das caixas e recuperáronse varios cravos (fig. 1). O tamaño reducido dalgunhas das fosas suxire enterramentos secundarios. A preservación dos esqueletos neste caso era moi mala, e non se puido facer máis que unha aproximación preliminar onde se identificaron 19 individuos dos 35 enterramentos (Franco Montesdeoca 2017).

Unha vez presentadas as necrópoles e os esqueletos, procedo a explicar os resultados dos estudos de reconstrución da paleodieta que foron posibles nos esqueletos das necrópoles de Santa María e San Bartolomeu, mentres que en San Domingos a mala conservación non permitiu a obtención de coláxeno ben preservado ata o momento. 


\section{ALIMENTACIÓN NA PONTEVEDRA MEDIEVAL A TRAVÉS DOS ISÓTOPOS ESTABLES}

O estudo dos resultados de reconstrución da paleodieta das necrópoles de Pontevedra foi publicado de maneira máis sucinta (López-Costas/Müldner 2019) como parte dun número especial sobre estudos de dieta na Península Ibérica e illas (López-Costas/Alexander 2019). Farei aquí un resumo dos principais resultados, mentres que os aspectos técnicos poden ser consultados na publicación (López-Costas/Müldner 2019). Dentro dos esqueletos conservados das dúas necrópoles, tomouse unha mostra de 63 adultos maiores de 9 anos para facer unha reconstrución da dieta. Ademais, eliximos 26 mostras de animais para coñecer os valores locais e aproximarnos á xestión do gando. Extraeuse coláxeno nunha mostra de óso, a maioría das veces pequenos fragmentos de costela no caso dos humanos, despois de desmineralizala, xelatinizala e liofilizala. Medíronse nun espectrómetro de masas os ratios de carbono-13 e nitróxeno-15 (os dous isótopos estables menos abundantes) con respecto á cantidade dos máis abundantes carbono-12 e nitróxeno-14. Os resultados preséntanse con respecto a un estándar coa notación $\delta^{13} \mathrm{C}$ para o carbono e $\delta^{15} \mathrm{~N}$ para o nitróxeno. Os valores de $\delta^{13} \mathrm{C}$ son sempre negativos ao ser o estándar usado un fósil cunha cantidade moi alta de ${ }^{13} \mathrm{C}$. O $\delta^{13} \mathrm{C}$ varía coa dieta rica en recursos mariños ou coas chamadas plantas $\mathrm{C}_{4}$, tales coma o millo miúdo ou o sorgo (ambos producindo valores altos ata $-10 \%$ ) ou recursos terrestres (valores baixos ata $-23 \%$ ). No caso do $\delta^{15} \mathrm{~N}$, os valores son positivos e varían entre a dieta baseada en vexetais (valores baixos arredor de 4 ou 8\%) e aumenta co consumo de produtos animais como a carne ou os lácteos (ata 15 ou 17\%o). Os números son orientadores e varían coas condicións ecolóxicas de cada zona, por iso é preciso analizar a fauna doméstica. Por outro lado, e co fin de evitar estar analizando moléculas contaminadas que sufrisen grandes cambios cos procesos postmortem, como a putrefacción do corpo ou as alteracións químicas relacionadas co ambiente de enterramento, faise un control estrito das mostras de coláxeno extraídas, desbotando aquelas que non cumpran cos parámetros de composición elemental típicos desta molécula. Unha selección de mostras de coláxeno foron analizadas con espectroscopia de infravermello e con pirólise GC-MS para detectar estas contaminacións e alteracións, e en ambos os dous casos se obtiveron bos resultados (Kaal et alii 2016, Martínez Cortizas/López-Costas 2020).

As mostras procesadas de gando son restos óseos de animais con marcas de ter sido consumidos (marcas de corte). Pertencen aos depósitos arqueolóxicos das dúas necrópoles de Santa María e San Bartolomé, xunto con mostras das escavacións na Praza de España preto da necrópole de San Domingos e das escavacións arqueolóxicas da Ponte do Burgo e da Ampliación do Museo de Pontevedra. Todas elas foron atopadas en estratos de contexto medieval, aínda que non é posible identificar con certeza o século. Analizáronse ósos de nove bois ou vacas (xénero Bos), catro ca- 
prinos (ovellas, cabras) e dous porcos (fig. 2). Todos os restos pertences a adultos salvo un caprino (cordeiro-cabrito) e un leitón. Estes dous teñen un sinal isotópico máis alto en $\delta^{15} \mathrm{~N}(12,2 \%$ e 9,6\% respectivamente), resultado da lactación dos primeiros meses de vida (o leite materno é un produto animal e, polo tanto, enriquecido en ${ }^{15} \mathrm{~N}$ ). $\mathrm{O}$ resto dos valores do gando doméstico herbívoro (Bos e caprinos) analizado é o esperable cun valor medio de $\delta^{13} \mathrm{C}$ de $-21,0 \pm 0,4 \%$ o $(\mathrm{n}=11)$ que vai desde $-21,9 \%$ ata $-20,5 \%$, e para un medio de $5,1 \pm 1,0 \%$, coas mostras entre $3,7 \%$ o e $7,3 \%$ o para $\delta^{15} \mathrm{~N}$. Isto interprétase como un gando probablemente local e homoxéneo no manexo que inclúe plantas das chamadas $\mathrm{C}_{3}$, que son a maioría dos pastos galegos. Excluímos o emprego de millo miúdo como forraxe ou o pastoreo en áreas moi próximas ao mar ou en marismas. $\mathrm{Na}$ tradición galega aparecen as papas de millo miúdo como alimento de animais preñados ou pequenos, sobre todo vacas e becerros (Moreno-Larrazabal et alii 2015); este feito non pode ser demostrado cos nosos resultados. Aínda ben, ha de terse en conta que a alimentación durante períodos curtos de tempo non é probable que teña un reflexo na variación do sinal isotópico dos ósos.

As vacas, bois ou becerros son moi homoxéneos (fig. 2) e polo seu tamaño é posible que proveñan de fóra da vila, dos pastos próximos. Os pastos, hortas e viñas que rodeaban Pontevedra estaban protexidos polo concello e destinados ao abastecemento da vila, tal e como se pode ver nas Ordenanzas de 1496 (Armas Castro 1992: 175), polo que é probable que o gando viñese dunha área de $20-30 \mathrm{~km}$. Pode que existisen pequenas diferenzas no manexo da cabras ou ovellas con respecto ás vacas, xa que as primeiras teñen os valores de $\delta^{15} \mathrm{~N}$ lixeiramente máis altos, sobre todo unha delas (fig. 2). Neste caso, as ovellas ou cabras precisan menos espazo para criárense, polo que poden provir de áreas familiares ou mesmo dos pequenos terreos arredor de Pontevedra. Un pasto moi fertilizado, por exemplo con bostas, ou manter os animais en cercados pequenos poden explicar o enriquecemento en ${ }^{15} \mathrm{~N}$; mentres que a introdución de carne bovina dependía das dúas carnizarías documentadas en período medieval, xa que, como nos indica a documentación, os prezos conservados son principalmente deste tipo de carne, e estas tiñan arrendadas terras preto da vila para proverse (Armas Castro 1992: 176). O único porco adulto analizado ten uns valores que entran dentro da media dos herbívoros (-20,4\%o e 6,6\%o; fig. 2), o que se traduce en que tiña unha alimentación eminentemente herbívora, sen acceso a refugallos cárnicos das cociñas, como é de esperar nun animal destas características nun período onde a carne e o leite escaseaban.

O noso estudo conta cun bo número de mostras de peixes da ría, algúns deles cun tamaño moi elevado, como é o caso das pescadas, que posuían grandes mandíbulas. Analízanse restos de tres pescadas, dous bonitos e, posiblemente, un sanmartiño e un pargo. Ademais, incluíuse unha vértebra de golfiño con marcas de corte, que confirman o seu procesamento para o consumo. Neste caso, o estudo 
isotópico informa dos valores dos recursos mariños locais no caso do $\delta^{13} \mathrm{C}$ cun medio de $-12,1 \pm 0,6 \%$ o $(n=9)$, mentres que o $\delta^{15} \mathrm{~N}$, cunha media de $12,7 \pm 1,9$, informa do nivel de carnivoría dos ditos animais, tendo en conta que a cadea alimentaria no medio mariño é sempre máis longa que a terrestre. Teñen un tamaño e nivel de carnivoría especialmente elevado as pescadas (fig. 2), o que é destacable, xa que esta especie forma parte das empregadas para a exportación. Polo tanto, vese que a fauna mariña procesada é probablemente local, da ría ou de rías próximas, e inclúe individuos de gran tamaño.

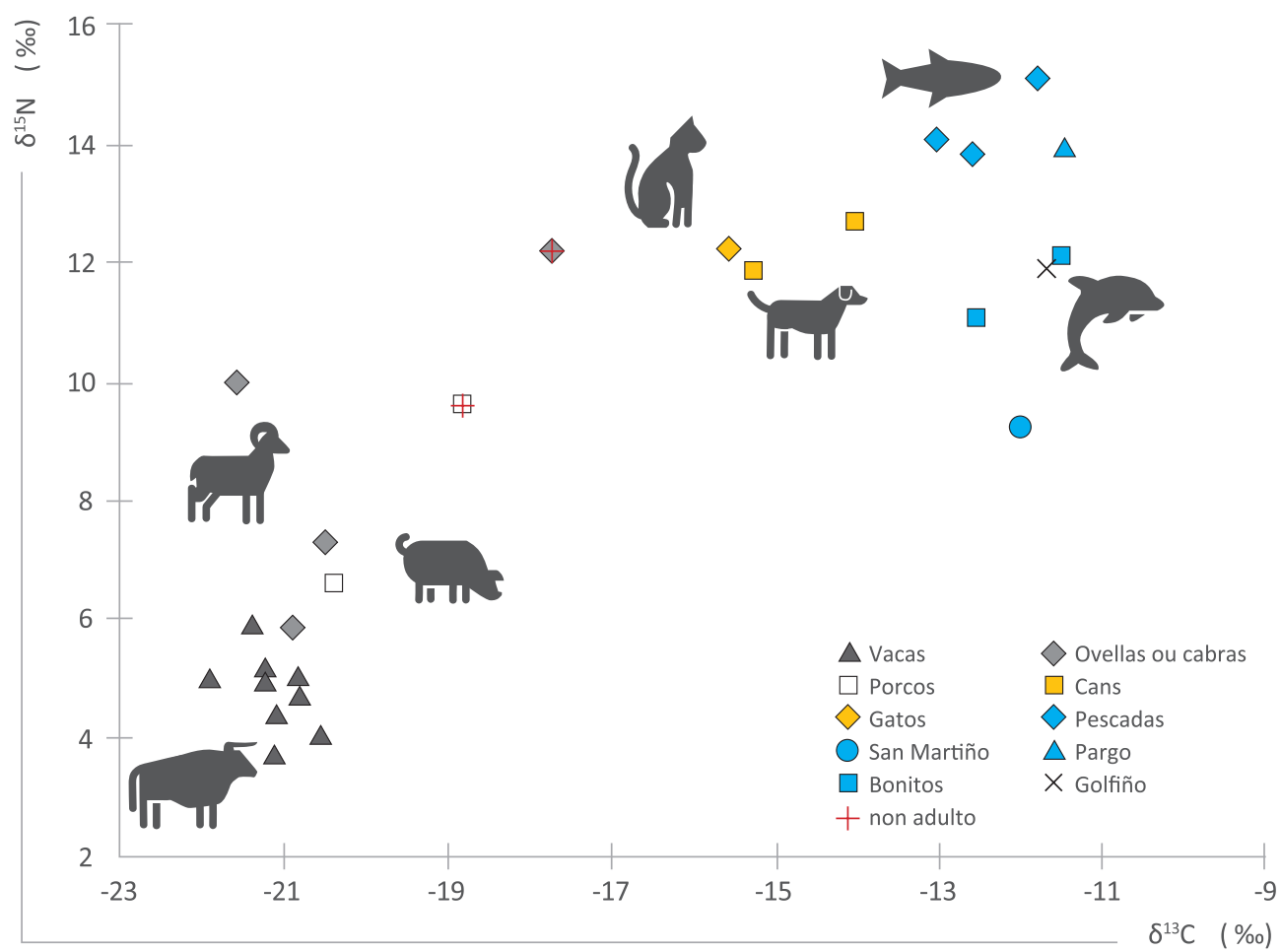

Fig. 2. Gráfico cos valores de isótopos estables da fauna analizada en Pontevedra.

Os animais domésticos, como cans $(\mathrm{n}=2)$ e gatos $(\mathrm{n}=1)$ atopados en contextos medievais dos xacementos da Praza de España e a Ponte do Burgo, teñen uns valores moderadamente altos en $\delta^{13} \mathrm{C}$ e $\delta^{15} \mathrm{~N}(-14,9 \pm 0,8 \%$ e $12,3 \pm 0,4 \%$, respectivamente) (fig. 2). Isto é interpretado como que ambos os dous tipos eran alimentados cunha boa cantidade de peixe ou outros recursos mariños, que probablemente eran os refugallos das casas, sen diferenzas claras entre cans e gatos. $\mathrm{O}$ alto consumo de peixe nestes animais, cunha dieta tan asociada á das persoas xa que conviven moitas 
veces nas casas, é un bo indicativo de ata que punto os recursos do mar eran de continuo consumo. No entanto, o feito de que os porcos non mostren valores compatibles con consumo do mar pode relacionarse con que viñan de granxas fóra de Pontevedra ou que tiñan vexetais dabondo nas hortas familiares para evitar empregar os restos de peixe como base da súa alimentación.

Con respecto ás mostras de humanos analizadas, xuntas caracterízanse por unha $\delta^{13} \mathrm{C}$ elevada, $-16,3 \pm 1,8 \%$, con respecto a outras mostras da Península Ibérica, pero similares ás medias atopadas na costa galega como as da Lanzada $\left(-16,0 \pm 1,5 \%\right.$ ) (López-Costas/Müldner 2016). Estes datos, xunto co $\delta^{15} \mathrm{~N}$ tamén relativamente alto $12,6 \pm 1,2 \%$, interprétanse como un forte consumo de recursos mariños e de plantas $\mathrm{C}_{4}$ (fig. 3). Os textos indican que a planta $\mathrm{C}_{4}$ de cultivo nas áreas que rodean a cidade é principalmente millo miúdo (Armas Castro 1992), que se corresponde con dúas especies, máis probablemente o Panicum miliaceum L. e menos abundante o paínzo ou Setaria italica L. Diferenzas no consumo de millo miúdo (caracterizado por elevado $\delta^{13} \mathrm{C}$ e baixo $\delta^{15} \mathrm{~N}$ ), marisco ou peixe pequeno (caracterizado por elevados $\delta^{13} \mathrm{C}$ e algo máis elevado $\delta^{15} \mathrm{~N}$ ) e peixe ou cefalópodos de tamaño grande (caracterizado por elevados $\delta^{13} \mathrm{C}$ e $\delta^{15} \mathrm{~N}$ ) poderían explicar a variabilidade nas mostras, así como a propia fisioloxía das persoas. Non obstante, esta xente tamén consumía plantas das chamadas $\mathrm{C}_{3}$, onde se incluirían a maioría dos cereais, verzas e legumes de cultivo tradicional en Galicia, mais non é probable que os produtos de orixe animal terrestre tales como lácteos, ovos ou carne abundasen na dieta dos pontevedreses do período medieval enterrados nos camposantos ao redor das dúas igrexas. Este feito último concorda coa información obtida dos documentos, onde se le o baixo número de carnizarías da vila (dúas; Armas Castro 1992: 176). Dos nosos datos podemos deducir, ademais, que os produtos animais derivados do gando doméstico eran máis ben escasos, que non constituían un grupo fundamental na mesa dos pontevedreses. Este tipo de alimentación cunha forte achega de produtos do mar e millos miúdos tan particular parece ser característico da costa galega e das Rías Baixas e diferénciase doutras áreas de Europa, onde, aínda que os recursos mariños chegaron a ser importantes, non constitúen, xunto co millo, un binomio tan forte na alimentación, nin sequera nas áreas costeiras ou nas illas.

Outro dos aspectos que destaca no estudo dos humanos son as diferenzas entre as mostras procedentes de Santa María e as de San Bartolomeu (fig. 3). No tocante a San Bartolomeu, analizáronse un total de 16 mostras probablemente pertencentes ao período (XIII-XV d. C.), cunha media de $-16,9 \pm 1,0 \%$ para $\delta^{13} \mathrm{C}$ (máximo, mínimo de $-15,2 \%$ e e $-18,7 \%$ o) e de $11,7 \pm 1,0 \%$ o $\left(12,9 \%\right.$ e 9,9\%o) para o $\delta^{15} \mathrm{~N}$. En Santa María temos 38 individuos asimilables ao período medieval ou, como moito, inicios da Idade Moderna (XIII-XV d. C.), cuns valores de $\delta^{13} \mathrm{C}$ de $-16,6 \pm 0,8 \%$ (cun máximo de $-14,6 \%$ e un mínimo de $-18,5 \%$ ) e $\delta^{15} \mathrm{~N}$ de $12,9 \pm 1,1 \%$ (desde $15,1 \%$ a a $9,6 \%$ ). Ademais inclúense no estudo 9 individuos atopados na primeira fase de enterramentos que pro- 
bablemente pertencen ao Período Moderno (séculos XVI-XVII d. C.), con valores (media de $-13,8 \pm 3,6 \%$ e $12,9 \pm 1,3 \%$ o) que se distribúen en dous grupos, como se observa na figura 3, cunha distribución moi ampla, sobre todo no caso de $\delta^{13} \mathrm{C}$, cun máximo que alcanza os 10,0\% e un mínimo de -20,3\%o (fig. 3).

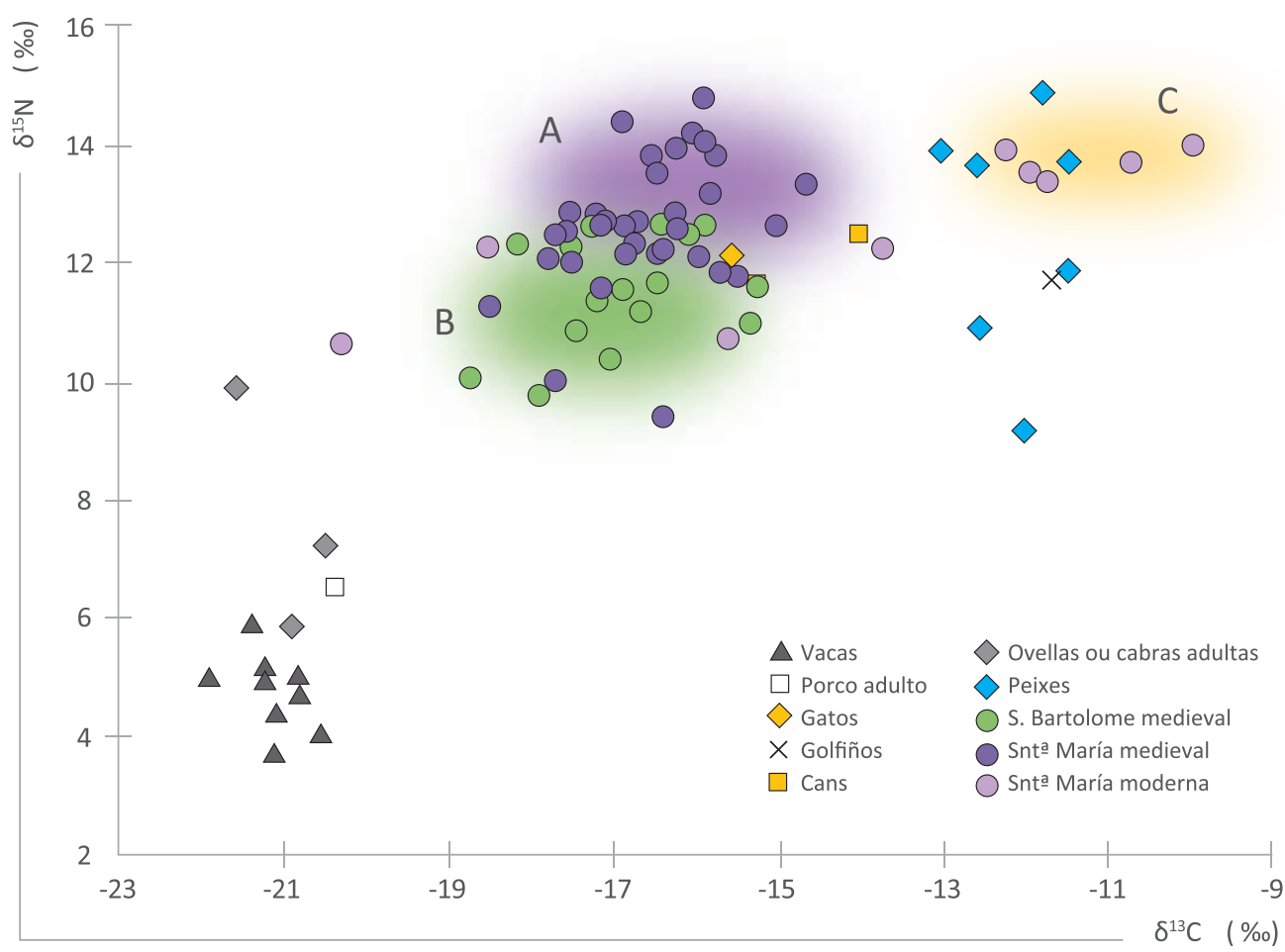

Fig. 3. Gráfico cos valores de isótopos estables das mostras de humanos analizados en Pontevedra. Os números remarcan a diferenza en $\delta^{15} \mathrm{~N}$ entre as fases medievais de Santa María (A) e San Bartolomeu (B), e os valores elevados en $\delta^{13} \mathrm{C}$ que caracterizan o forte consumo de millo das Américas nalgún individuo das fases finais de Santa María (C).

Para o período baixomedieval (séculos XIII ao XV), as diferenzas entre mostras son estatisticamente significativas en $\delta^{15} \mathrm{~N}$ pero non no $\delta^{13} \mathrm{C}$. Este dato sorprendeunos ao principio xa que, como os fregueses de Santa María pertencían ás familias vencelladas co mar, agardabamos que estes tivesen un maior consumo de produtos mariños. Na figura 3 obsérvase esa tendencia a que estas mostras teñan uns valores lixeiramente máis elevados en ${ }^{13} \mathrm{C}$, pero, como se indica, non son significativas por que hai un nivel de solapamento alto. A alta dependencia da cidade dos alimentos mariños fixo moi probablemente que todos os seus habitantes (polo menos as familias gremiais) tivesen un acceso directo a eles e constituísen a base do seu consumo. 
Destacamos a este nivel que non se observaron diferenzas cando se compararon mostras procedentes de esqueletos de ambos os dous sexos (o sexo do esqueleto pode tomarse, con algunhas precaucións, como indicativo do xénero) e as diversas idades. Neste último caso, temos en conta que a persoa máis nova incluída no estudo tiña de 9 a 12 anos de idade estimada, estando a maioría dos oito non-adultos entre os 16 e os 20 anos. Isto fíxose para evitar no posible o sinal do período de lactación (o leite materno eleva o $\delta^{15} \mathrm{~N}$ ) e na actualidade estamos facendo novos estudos para determinar a idade de desteta e aproximarnos máis á dieta na infancia. Polo tanto, podemos afirmar que homes e mulleres, así como desde a mocidade ata a vellez (3 individuos superaban os 60 anos de idade biolóxica estimada), consumían sen diferenza os mesmos produtos. Aínda que esta técnica non é capaz de detectar diferenzas na cantidade, pódese asumir que as familias compartían mesa e acceso aos recursos. Nunha pesca dominada pola baixura, os homes virían con probabilidade comer ás súas casas, o que explicaría a falta de diferenzas por sexo e idade.

Pero, a estas alturas, como podemos explicar que as diferenzas entre os períodos medievais das dúas igrexas sexan, principalmente, no $\delta^{15} \mathrm{~N}$ ? A resposta que nos parece máis probable ten que ver co tipo de peixe ao que se tiña acceso. Na Pontevedra dos séculos do XIII ao XV d. C., non todos os produtos mariños servían para o comercio. Existen unhas especies que son secadas ou afumadas para a súa preservación: a pescada, o congro e o polbo, así como a sardiña, que normalmente se conservaba en salgadura (Armas Castro 1992: 146). A documentación indica que estes procesados se importaban a diversas áreas de Europa, incluída a Valencia islámica e cristiá (Ferreira Priegue 1987). Trátase de dous procesos diferentes que conducen ao incremento do ${ }^{15} \mathrm{~N}$ nos comensais. No caso da pescada e congro, elixíanse os individuos de máis tamaño entre estes animais, de por si grandes depredadores, polo que o seu nivel de carnivoría elevado fai pensar que terían un $\delta^{15} \mathrm{~N}$ alto (tal e como se observa nas mostras de pescada analizadas). As sardiñas, polo tamaño, non terían estas características pero o sal fai que os corpos acumulen máis ${ }^{15} \mathrm{~N}$, tal e como se observa nas áreas con abundantes salinas ou lagos salgados, como determinamos nun estudo que fixemos en Écija (Sevilla) (Inskip et alii 2019). Polo tanto, o consumo de peixe preservado en salga produciría o mesmo efecto. A nosa hipótese é que as familias da freguesía de Santa María tiñan acceso a estes produtos destinados á exportación e ricos en ${ }^{15} \mathrm{~N}$ xa que se encargaban de pescalos e procesalos nos baixos das casas, mentres que as familias dos gremios de artesáns de San Bartolomeu terían acceso ao peixe e mariscos non destinados á exportación, sendo estes caracterizados polo mesmo sinal $\delta^{13} \mathrm{C}$ pero cun $\delta^{15} \mathrm{~N}$ máis baixo.

Finalmente, obsérvase que no último momento de enterramentos en Santa María (séculos XVI-XVII), a dieta diversifícase moitísimo (fig. 3), incluíndo algúns individuos moi enriquecidos en ${ }^{13} \mathrm{C}$. Ao final do século XV introdúcense novas artes de pesca, tales como a pesca do cerco, que permite atrapar os cardumes de sardiñas case enteiros. A sobreexplotación da ría causou a falta de sardiñas documentada nos 
anos 1525, 1550, 1575 e 1595 (Filgueira Valverde 1991, Juega Puig 2012). Xusto nese momento, a produción de cereais baixou, entre outras razóns polo empeoramento das condicións climáticas na recrudescencia da Pequena Idade do Xeo (Martínez Cortizas et alii 1999). Ademais, a cidade de Pontevedra vai perder a súa predominancia na costa sur galega, pola existencia de regulacións moi pechadas, que foran útiles nos séculos anteriores (Pereira Fernández 1997, Juega Puig 2012). Outros portos do sur de Galicia, como os de Vigo ou Noia, ocuparán o lugar da vila pontevedresa e dos seus habitantes na política e economía galega, que sufrirán as consecuencias deste ocaso en forma de diversos períodos de fame no século XVI e, sobre todo, no XVII. Os impostos excesivos e a rixidez das institucións fixeron que esta vila levase peor os períodos de carestía, polo que a maioría do peixe é destinado a pagar as taxas (Pereira Fernández 1997), que antes eran pagadas en forma de viño (Pereira Fernández 1997, Juega Puig 2012). O concello arrenda barcos con cereais para alimentar a poboación nos peores momentos e prodúcese a entrada dun cereal de alto rendemento que fai paliar esta fame: o millo das Américas. O millo americano é cultivado nos campos arredor de Pontevedra pero tamén traído desde Asturias por barco desde polo menos o ano 1612 (Juega Puig 2012) -chámase, neste caso, o «pan do mar». Este cereal caracterízase por ter un moi elevado $\delta^{13} \mathrm{C}$, o que se transmitiría aos tecidos humanos, tal e como se observa nos valores extremadamente altos atopados nos enterramentos da fase moderna de Santa María (fig. 3, área C).

\section{A VIDA NA PONTEVEDRA MEDIEVAL}

Nestas liñas tratei de expoñer como a cidade de Pontevedra se converteu no século XIII nun núcleo político e mercantil de primeira orde. Os privilexios reais, ratificados entre outros polo rei Afonso X, permitíronlle dominar o comercio de produtos mariños na Península e en boa parte de Europa. Os barcos pontevedreses do século XIII entraron nos principais portos estranxeiros, incluídos Holanda e Inglaterra (Armas Castro 1992). Estas actividades da pesca e os seus derivados, como o proceso de salga ou de afumado do peixe, foron exercidas principalmente polos habitantes da vila (Juega Puig 2012), e así parece que lles quedou marcado nos ósos.

A evolución de Pontevedra, estimulada polos privilexios e exencións reais e pola riqueza da súa ría (Armas Castro 1992: 59), fixo que medrasen os seus barrios paralelos ao crecemento da igrexa de Santa María a Maior, e á orixe e expansión da freguesía de San Bartolomeu. Os gremios e o concello van determinar a vida na vila limitando as importacións e asegurando a subministración equitativa dos bens básicos (Armas Castro 1992). Esta equidade obsérvase na reconstrución da alimentación a través dos esqueletos (López-Costas/Müldner 2019). Os cemiterios de Pontevedra e 
os seus esqueletos son un fiel reflexo dos seus fregueses, especialmente do seu poder económico no caso dos tipos de enterramento e as diferenzas na distribución do espazo entre San Domingos, San Bartolomeu e Santa María. Aínda que semellantes na súa evolución, as dúas últimas necrópoles mostran variacións na alimentación. Estas parecen estar vencelladas ás actividades das familias e ao maior acceso a produtos destinados á exportación, como pescadas de gran tamaño, congros e polbos, ou sardiñas salgadas ou saín, por parte dos habitantes dos barrios asociados a Santa María. Os artesáns de San Bartolomeu e as súas familias terían acceso a un peixe de menor tamaño e de consumo fresco.

Finalmente, reflexionamos sobre a especificidade da dieta na costa galega, que parece ter mantido un padrón dominado polos recursos do mar, peixes e mariscos, e o consumo de vexetais, incluíndo unha boa cantidade de millo miúdo. Ao contrario doutras áreas como Asturias, os millos destínanse aquí preferentemente para consumo humano, e non para o gando. A riqueza das rías galegas ten na cidade de Pontevedra e na súa evolución no século XIII un exemplo moi ilustrativo. Así mesmo, a decadencia dos séculos XVI e XVII serve como mostra da fraxilidade destes ecosistemas e da importancia de optar por políticas flexibles adaptadas á preservación da nosa terra e das súas xentes.

\section{AGRADECEMENTOS}

Os meus agradecementos á delegación de Patrimonio Histórico da Xunta de Galicia por apoiar os estudos nestes xacementos, así como ao Museo de Pontevedra polo apoio ao traballo con restos humanos en Pontevedra e noutras necrópoles da provincia. O estudo isotópico foi feito coa colaboración de Gundula Müldner, da Universidade de Reading. Grazas a Juan Carlos Castro, Xavier Chao e Xurxo Constela, así como aos demais integrantes das empresas de arqueoloxía Anta de Moura, Tomos e Citania polo traballo ben feito no campo e a axuda prestada nestes anos. Grazas a Pedro López Barja polos seus comentarios a unha versión previa do manuscrito. O meu agradecemento a Simon R. Doubleday pola invitación a participar neste libro e as súas suxestións ao texto, e a José Armas Castro por ter escrito o seu. 


\section{REFERENCIAS BIBLIOGRÁFICAS}

- Álvarez-Fernández, Noemí/Antonio Martínez Cortizas/Olalla López-Costas (2020): «Atmospheric mercury pollution deciphered through archaeological bones», Journal of archaeological science, 119, 105-159.

- ARMas Castro, José (1992): Pontevedra en los siglos XIII a XV, configuración y desarrollo de una villa marinera en la Galicia Medieval, Pontevedra, Fundación Pedro Barrié de la Maza Conde de Fenosa.

- Blanco Freijeiro, Antonio/Miguel Fusté Ara/Alfredo García Alén (1961): «La necrópolis galaico-romana de La Lanzada (Noalla, Pontevedra), I», Cuadernos de Estudios Gallegos, 16, 141-158.

- Campillo, Domingo (1993): Paleopatología. Los primeros vestigios de la Enfermedad. Parte primera, Barcelona, Fundación Uriach, 1838.

- CARro Otero, José (1971): Anatomía antropológica antigua del Pueblo Gallego: Siglos I al VII d.C. Tese de doutoramento. Universidade de Santiago de Compostela.

- CONSTEla Doce, Jorge Juan (2007): «Actuación arqueolóxica no marco da rexeneración do arrabalde de Santa María, zona intramuros, Pontevedra. Informe valorativo (CD 102A 2007/196-0)». Orixinal depositado na Consellería de Cultura e Deporte. Dirección Xeral de Patrimonio. Xunta de Galicia.

- Constela Doce, Xurxo (2008): «Informe valorativo da Escavación en área do ámbito do aparcamento subterráneo proxectado na Praza de España da cidade de Pontevedra. Citania Arqueoloxía S.L.». Orixinal depositado na Consellería de Cultura e Deporte. Dirección Xeral de Patrimonio. Xunta de Galicia.

- Chao Álvarez, Francisco Javier (2008): «Actuación arqueolóxica no marco da rexeneración do arrabalde de Santa María, zona intramuros, Pontevedra. Escavación arqueolóxica das gabias de instalación nos sectores 1 e 3. 1B e 3A, B, C. Informe valorativo (CD 102A 2007/698-0)». Orixinal depositado na Consellería de Cultura e Deporte. Dirección Xeral de Patrimonio. Xunta de Galicia.

- Fernández Villamil, Enrique (1942): «Privilegios reales del Museo de Pontevedra», El Museo de Pontevedra, 132-174.

- Ferreira Priegue, Elisa María (1987): Galicia en el comercio marítimo medieval, A Coruña, Fundación Pedro Barrié de la Maza. (Colección Documentos históricos).

- Filgueira Valverde, José (1991): La basílica de Santa María de Pontevedra, A Coruña, Fundación Pedro Barrié de la Maza, Conde de Fenosa.

- Franco Montesdeoca, Álvaro (2017): «Trabajo Fin de Máster: Estudio de la necrópolis de Santo Domingo en Pontevedra». Universidade de Santiago de Compostela.

- Inskip, SARAH/Gina CARROLL/Andrea WATERs-Rist/Olalla López-Costas (2019): «Diet and food strategies in a southern al-Andalusian urban environment during 
Caliphal period, Écija, Sevilla», Archaeological and Anthropological Sciences, 11, 3857-3874.

- JuEga Puig, Juan (2012): «El comercio marítimo en Galicia 1525-1640», Obradoiro de Historia Moderna, 21, 105-130.

- KaAL, Joeri/Olalla LóPEZ-Costas/Antonio MarTínez CortizAs (2016): «Diagenetic effects on pyrolysis fingerprints of extracted collagen in archaeological human bones from NW Spain, as determined by pyrolysis-GC-MS», Journal of archaeological science, 65, 1-10.

- LARSEN, Clark Spencer (2002): «Bioarchaeology: The Lives and Lifestyles of Past People». Journal of Archaeological Research, 10, 119-166.

- LóPEZ-Costas, Olalla (2008): «Resumen anual ano 2008 do proxecto “Antropoloxía dos restos óseos humanos de Galicia [...]”. Unpublished work». Orixinal depositado na Consellería de Cultura e Deporte. Dirección Xeral de Patrimonio. Xunta de Galicia.

- López-Costas, Olalla (2012): Antropología de los restos óseos humanos de Galicia: estudio de la población romano y medieval gallega. Tese de doutoramento. Universidad de Granada.

- LóPEz-Costas, Olalla/Michelle ALEXANder (2019): «Paleodiet in the Iberian Peninsula: exploring the connections between diet, culture, disease and environment using isotopic and osteoarchaeological evidence», Archaeological and Anthropological Sciences, 11, 3653-3664.

- LÓPEZ-COSTAS, Olalla/Gundula MüLDNER (2016): «Fringes of the empire: Diet and cultural change at the Roman to post-Roman transition in NW Iberia», American Journal of Physical Anthropology, 161, 141-154.

- López-Costas, Olalla/Gundula MüLDNER (2019): «Boom and bust at a medieval fishing port: dietary preferences of fishers and artisan families from Pontevedra (Galicia, NW Spain) during the Late Medieval and Early Modern Period», Archaeological and Anthropological Sciences, 11, 3717-3731.

- López Ferreiro, Antonio (1895): Fueros municipales de Santiago y de su tierra, Santiago de Compostela, Seminario Central.

- MÁrquez-Grant, Nicholas/Carme Rissech/Olalla LóPEZ-Costas/Inmaculada Alemán/Luis CARO DobÓN (2011): «Spain/España», en N. MÁrQueZ-GRANT/ L. FIBIGER (coords.), The Routledge Handbook of Archaeological Human Remains and Legislation: an international guide to laws and practice in the excavation, study and treatment of archaeological human remains, London, Routledge, Taylor and Francis Group, 423-438. 
- MARTínez Cortizas, Antonio/Olalla LóPEz-COSTAS (2020): «Linking structural and compositional changes in archaeological human bone collagen: an FTIR-ATR approach», Scientific Reports, 10, 17888.

- Martínez Cortizas, Antonio/Xavier Pontevedra-Pombal/Eduardo García-RodEjA/Juan C. NOvOA-MUÑOZ/William SHOTYK (1999): «Mercury in a Spanish peat bog: Archive of climate change and atmospheric metal deposition», Science, 284, 939-942.

- MÉndez MarTínez, Gonzalo (1988): «La morfología urbana de Pontevedra hasta 1900», en R. Villares (coord.), La ciudad y el mundo urbano en la historia de Galicia, Tórculo, 253-268.

- Moreno-LaRrazabal, Aitor/Andrés Teira-Brión/Itsaso SoPElana-Salcedo/Amaia ARRANZ-OTAEGUI/Lydia ZAPATA (2015): «Ethnobotany of millet cultivation in the north of the Iberian Peninsula», Vegetation History and Archaeobotany, 24, 541-554.

- Pereira Fernández, Xosé Manuel (1997): «Pontevedra en el siglo Xvi. Contribución al estudio de la historia urbana de Galicia», Obradoiro de Historia Moderna, 6, 239-262.

- Sarmiento, Fray Martín (1950): Viaje a Galicia, Ms. de la Abadía de Silos 1754-1755, Santiago de Compostela, Instituto Padre Sarmiento de Estudos Galegos.

- Wood, James W./George R. Milner/Henry C. HARPENDing/Kenneth M. WeISS/Mark N. COHEN/Leslie E. EISENBERG/Dale L. HutChINSON/Rimantas JANKAUSKAS/Gintautas ČESNYS/M. Anne KaTZENBERG/John R. LUKACS/JANET W. MCGRATH/Eric ABELLA RotH/ Douglas H. UbeLAKER/Richard G. WILKINSON (1992): «The Osteological Paradox: Problems of Inferring Prehistoric Health from Skeletal Samples (and Comments and Reply)», Current Anthropology, 33, 343-370. 
